\title{
Roadmap for the Delivery of Cancer Care in Rural India
}

\author{
Arun S. Ninawe* \\ Advisor (Scientist 'G'), Department of Biotechnology, India
}

*Corresponding Author: Arun S. Ninawe, Advisor (Scientist 'G'), Department of Biotechnology, India, Email: ninawe@gmail.com

\section{INTRODUCTION}

In simple terms, cancer is an abnormal growth of body cells. However, when the programming of a cell or a group of cells is affected, growth may become uncontrolled. Some of the factors that are made responsible for chronic irritation, tobacco, smoke and dust, radioactive substances, age, sex, race and heredity. These are the reasons that could be responsible for cancer. Prevention is definitely better than treatment of cancer. As reported in India, there are various types of cancers namely: oral cancer, cervical cancer, breast cancer, colorectal cancer, lung cancer etc. The human body is made of trillions of cells. The activity of cellular growth is controlled by a cellular clock that allows them to survive, divide, multiply, carry out different functions, grow and finally die. The DNA within the cells contains a genetic code that controls such activities. When this code is altered the orderly cellular clock function is lost resulting, in cells that keep multiplying but do not die and can spread in to surrounding issues. When cancer sets in, a group of cells suddenly starts multiplying in a haphazard and uncontrolled way, forming lumps or tumours.

The overall incidence of cancer is increasing in India at steady pace. Unfortunately due to large population, even a minor increase in the rate of incidence translates into a large number of cancer affected individuals. According to ICMR 14.5 lakhs new cancer cases are expected by 2016 and are likely to reach 17.3 lakhs in 2020. Over 7.36 lakhs will die due to cancer in 2016 and increasing to 8.8 lakhs by 2020 . It is only $30 \%$ of the diagnosed patients survive 5 years or longer as only $12.5 \%$ present in early stages for treatment across the country.

Taking example of Mumbai Cancer registry, in the year 2014, Mumbai cancer registry documented 13564 new cancers in Mumbai and
7023 deaths due to cancer. The majority was seen in seniors the age above 60 years. The single greatest risk factor for developing cancer is ageing. Prolonged exposure to carcinogens, reduced DNA repairing ability, genetic instability, decreased carcinogens metabolism and decreased immune surveillance dramatically increase the incidence of cancer in the elderly. At younger ages 263 children above 14 years and 26 young adults 15-34 years were affected. The gastrointestinal tract was the commonest site of cancer. There is no definite way of preventing cancer. However, a healthy lifestyle, eating, correctly with adequate vegetables and fruit in the diet and regular exercises can have beneficial effects on the overall health of cancer patients. Obesity is an important and causative factor, thus maintaining a proper BMI would be a sensible approach to cancer prevention and early diagnosis. In India, the number of cancer patient is around 28 lakhs and increasing at the alarming rate. There is an increase of 1.1 million every year and the number of deaths is half a million. Governments and civil society organizations have alleviated the sufferings of cancer patients and creating awareness on affordable cure methods. The key is in prevention and therefore, all the stakeholders must work towards prevention and early detection.

\section{CANCER DEMOGRAPHICS IN INDIA}

In next 30 years, it is estimated that India is likely to double the cancer patients. This increase is not as much as because of true increase in the incidence of cancer, but mainly because of increase in our population. The improvement in facilities helping in diagnosis and to improve the lifespan of the Indian population, increased from 45 years to 66 years since independence. The cases of cancer detected in India are low as compared to 
developed nations, but mortality rate is high. Statistics showed that $68 \%$ patients with cancer die in India as compared to only $33 \%$ in the United States. The higher incidence of cancer cases are reported in rural India and are at the alarming rate because of changing lifestyles and urbanization of rural India. This is due lack of adequate cancer facilities available in rural India.

\section{ACCESS TO CANCER CARE}

Registry research and education has contributed significantly in providing information for planning implementing and monitoring cancer control input and evaluating cancer control outcome. The cancer registries helped in understanding the magnitude and trends in cancer occurrence and plan control activities through National Cancer Control Programme. Global comparison shows that India has high incidence rates of cancers of oral cavity, pharynx, \& cervix. The National Cancer Control Programme came in to existence in 1975-76 with the initial emphasis on treatment and cure. ICS is creating awareness on prevention and early diagnosis treatment and support psychosocial barrier. It is taking several path breaking initiatives including the establishment of the first cytology and chemotherapy units, rehabilitation unit for survival, organizing cancer congress, creation of awareness and early detection programmes and supporting the establishment of the cancer registry in India. They have been helping through Government medical institutes for early detection, screening and prevention. The changes could be seen with rapid advancement in medical science and technology, the survival rate and the quality of life which has been significantly improving.

HelpAge India, also serves as a cancer care charity for elders. Their biggest challenge is to provide sustained healthcare intervention for needy elderly cancer patients. As the treatment costs are very high, many cancer patients are not able to complete cancer treatment. Many of elderly are unable to collect the necessary funds for cancer treatment and do not opt for treatment. HelpAge India in partnership with number of credible and competent cancer hospitals and organisations are carrying out cancer treatments which include cancer surgeries, radiation and chemotherapy. These partners also conduct cancer awareness and cancer detection camps. HelpAge India providing services to elders and 25,000 elderly have been screened for cancer and over 10,000 treatments provided.

\section{Cancer In North-East Regions OF INDIA}

In northeast India, a very high incidence of cancers reported in general and tobacco and pesticide related cancers in particular. Large numbers of cases have been reported in NorthEast region of India. However, the available data on tobacco usage and pesticide exposure alone is not sufficient to explain the high incidence. North-East region of India has different customs, food habits, life-style, diverse ethnic groups, and type and pattern of tobacco use in as compared to the rest of the country. The carcinogenicity of tobacco is attributed to nitrosamines, PAHs, benzene, Benzo (a) pyrene etc. Also extensive use of pesticides in tea gardens in North-East which can lead to widespread occupational and environmental exposures. ICMR has set up Cancer Registries in the North-East under the NCRP (National Cancer Registry Programme). These centres have good working relationship with the populations harbouring the cases of cancers and have earlier provided data, showing the high prevalence of certain types of cancers in these regions. Multi centric studies have been initiated by ICMR to find out the genetic factors, in addition to common environmental exposures, tobacco smoking, alcohol consumption, pesticide exposure and dietary habits which could possibly explain the high prevalence of certain cancers in North-East India.

\section{AWARENESS DRIVE}

The rising incidence of cancer, it has been essential to raise awareness among the general population on cancer literacy, particularly the early sign and symptoms. Also to educate people about the regular check-ups as many cancers are curable and detected at early stages. As a part of awareness drive, social media educates the community through videos and posting messages through educational films on occurrence of cancer, its intensity due to breast, cervical, oral of smoking and chewing habits etc. Government institutions conduct mobile screening camps for early diagnosis for the investigation of common cancer in poor rural community. The awareness programmes help the patient to detect the disease and visit to a doctor. In India the incidence is rising because people are now aware of the symptoms and are coming forward to seek the help. A mass screening programme in government as well as 
private hospitals are being organized. Bringing awareness on the curability of childhood cancer provides monitoring of the late effects of cancer therapy and empowers survivors through educational and vocational support.

Cancer care is becoming expensive day by day, and in India where most of the healthcare is selffunded, most of the patients do out-of-pocket payments for cancer care. It is beyond the reach of most rural patients to take cancer treatment on their own. The help of the non-governmental organizations has been very ironical for their timely help in financial or logistic support.

\section{FinANCIAL AID \& RESOURCES}

The Ministry of Health \& Family Welfare offers financial assistance to poor patients. Funds are available for patients living below the poverty line. A maximum of Rs. 50,000 provided to poor patients for hospitalisation/ treatment in government hospitals with free medical facilities. The Central Government Health Scheme (CGHS) is applicable for retired Central Government employees and dependents, which offers coverage for cancer treatment at approved rates from any hospital, apart from the hospitals set up under CGHS. Indian railway offers completely free travel to cancer patients and the attendant to pay only $25 \%$ of Class II fare. Air travel concession of $50 \%$ is offered to patients travelling for treatment. The needy patients have been provided financial aid for the treatment of under privilege patients. Corporate such as SBI foundation and Union Bank of India have also started treatment fund to help patients who are unable to afford the diagnostic test and visit the hospital when the cancer is at an advance stage.

\section{INSURANCE POLICY}

Indian Cancer Society and The New India Assurance Company Limited (NIA) have pioneered cancer specific insurance policy to benefit large sections of people. The policy offered by New India Assurance is unique and extremely cheap compared to general health insurance policies. It can also be taken as an 'Add on' to top up your existing health policy. This insurance policy is open to any person upto 70 years provided they have had no cancer earlier. According to the agreement with NIA, anyone who wants to avail of this cover has to become a member of the Indian Cancer Society. As the number of cancer cases in India are raising the number of Tertiary Cancer Centres with excellent infrastructure and trained oncologists are also increasing in urban India.
However the same is not true about rural India. This is reflected in the fact that, though the incidence of cancer in rural India is nearly half of that of urban India, the mortality rates are double in the rural areas.

In North-Eastern and Hilly States the Central Government is contributing $10 \%$ of grant for training, rehabilitation and counselling. Besides National Programme for Prevention and Control of Cancer, Diabetes, Cardiovascular Disease and Stroke (NPCDCS) also support the prevention measures. Apart from the Government's efforts to fight against cancer, doctors in the private sector from time to time conducts awareness camps, formulate better programmes and strategies to benefit to the survivor. The tests are done free of cost and the suspected cases identified are further assisted in diagnostic testing and treatment in the nearest cancer hospital.

\section{REAL DRAWBACK IN RURAL TREATMENT}

Nearly $70 \%$ of Indian population lives in rural India. However, nearly $95 \%$ of cancer care facilities are in urban India. Moreover, cancer treatment in our country is highly priced and health insurance only benefits the upper and middle classes. In most cancer hospitals, needy elderly patients have to wait for months for diagnosis, preparing funds, seeking expert opinion and getting appointments from surgeons. Insufficient cancer treatment facilities and lack of early screening, resulting from poor public health system in the country has led to large numbers of cancer cases reported to too late. Because of financial constraints and cultural barriers, these patients present late to the Tertiary Cancer Centres (TCCs). Most TCCs are overcrowded, and because of decreased manpower and limited infrastructure, there are further delays in treatment. There are few facilities disseminating cancer awareness, early detection and early diagnosis in rural regions. Even the biopsies or the blood samples are sent to cities and the reports take weeks to come back. By the time, the patient can arrange the logistics to go to cities for treatment; it causes further delays in treatment and advancement of the disease because these patients come with advanced disease. Because of poor outcomes, other rural patients are not motivated to take proper treatment on time. 


\section{DeVElopMENT OF RURAL TERTIARY Cancer Centres}

The development of RCC would help urban TCCs take better care of patients by providing services of onco-surgeon, radiation oncologist, medical oncologist and onco-pathologist at rural center at regular intervals and also arrange to train local doctors at the TCC. The availability of Skype, Webinar, telemedicine facilities, interval consultations, courier services and pathology slides/blood samples from RCCs would also help to save time and reporting. The students of oncology specialties who train at TCC should be rotated through RCC to understand and learn optimum utilization of basic infrastructure offering the best outcome in the absence of expensive, Hi-tech Intervention in implementing cancer care. The rehabilitation centres provided various survivorships to rehabilitate cancer patients and survivors. It produces survival cancer rehabilitation kit, prosthetic, orthotic appliances, aids and appliances for disabilities. The psychosocial and community adjustment service provides vocational rehabilitation and skill training along with counselling for the patients and their family members.

The Ministry of Health and Family Welfare, Government of India has formulated a National Program for Prevention and Control of Cancer, Diabetes, Cardiovascular disease, and Stroke after integrating the National Cancer Care Program (NCCP) with other non-communicable diseases. The initiatives of CSR are well appreciated for the under privileged who have no support for the treatment. This includes corporate, entrepreneur, financial institutions and NGOs. The NGOs have been working across the cancer spectrum giving more focus on mass education, creating better understanding of the disease to fight with the battle of cancer in general populations.

The Tata Memorial Centre (TMC), one of the largest comprehensive cancers in Asian subcontinent. It has commissioned a model rural cancer control programme for Rural Outreach and conducting programme in Ratnagiri and Sindhudurg districts of Maharashtra during the last 13 years. The goal is to create health awareness about all cancers in general and specifically treatment on oral, breast and cervical cancers. Service for precursors/early stages of cervix, breast and oral cancer among women, and oral cancer among men were carried out and the cases detected through screening camps. At rural centres, many patients present with advanced disease and many others need palliative care. Thus, it is very important that each of these rural cancer centres are equipped with radiotherapy facilities. The awareness creation on cancer and prevention helps through introduction of simple costeffective methods and by the execution of paramedics.

\section{RESEARCH INTERVENTIONS IN CANCER CURE}

In view of supporting national priorities, the focus of research in the field of cancer has been on the aetiology with identification of preventable risk factors that understand the mechanism of carcinogenesis and on operational research. The multidisciplinary research involved clinical, epidemiological as well as basic sciences including modern molecular techniques. The Institute of Cytology and Preventive Oncology (ICPO) carried out two long term prospective studies on uterine cervical dysplasia (UCD-I and UCD-II), to understand the natural history of cervical cancer. Over the years ICPO developed the required infrastructures to carry out in depth studies for cervical cancer such as accredited cytology laboratory for teaching, training and diagnostic purposes, centralised colposcope facilities. The studies undertaken on cancer research correlate with epidemiological risk factors with molecular, cellular and biochemical changes. The applications of sensitive modern biological tools are helping in finding the role in aetiology and progression of the disease.

\section{STRATEgY}

In the present time the major emphasis is given on cancer care in smaller cities and in rural areas. National Health Policy, 2017 focus on preventive and promotive health care and universal access to good quality health care services. This is for achieving universal health coverage and delivering quality health care services to all at affordable cost. To address the important challenges on cancer cure in India it is felt strengthen emphasis on the followings:

1. There is need to give stress on cancer prevention by developing cost-effective screening techniques for early detection, developing indigenous radiotherapy equipment, use of generic drugs, and also going after drug repurposing rather than drug discovery. 
2. Take initiatives of research between modern medicine and traditional therapies like Ayurveda, Homeopathy, Unani for widely acceptance of the therapy in the country in an integrated manner.

3. Strengthening of health, surveillance system and establishment of registry of diseases of public health importance also supports through voluntary services involving agencies like Indian Cancer Society to spread awareness, detection, cure and treatment for cancer patients.

4. It would be very important to link all these rural cancer units across India through the National Cancer Grid (NCG) to allow the exchange of expertise between centres and to create a ready network of centres for collaboration research in cancer.

5. As projected, the real success of NCG will be apparent when overall cancer outcomes in India improve considerably, parallel with patients getting the highest quality cancer care at their door step.

6. These rural cancer centres should also have a registry attached to it since estimating the cancer burden not only helps us to formulate policies, but also to gear-up for further management strategies.
7. The registry should cover not only cancer cases and it needs to be extended to other common non-communicable diseases with more or less similar etiological functions like cardiovascular disease and diabetes and stroke under the National Centre for Disease Informatics and Research.

\section{REFERENCES}

[1] C S Pramesh et.al; (2014) Cancer burden and health systems in India 3: Delivery of affordable and equitable cancer care in India; Published online April 11, 2014 http://dx.doi.org/10.1016/S14702045(14)70117-2

[2] Anon, 2017 ; National Health Policy 2017; Source: Department of Health \& Family Welfare, Ministry of Health \& Family Welfare, Government of India; Document pp-1-28

[3] https://www.helpageindia.org/ourwork/program s/cancer-care.html

[4] Cancer in North-East Regions of India; Annual Report 2003-05; Institute of Cytology and Preventive Oncology; pp-48-55

[5] http://www.indiancancersociety.org

[6] Call for Action: Expanding cancer care in India; Report Published by Ernst \& Young LLP (2015); pp-1-91

Citation: Arun S. Ninawe. Roadmap for the Delivery of Cancer Care in Rural India. ARC Journal of Cancer Science 2017; 3(1):29-33. DOI: http://dx.doi.org/10.20431/2455-6009.0301005.

Copyright: () 2017 Authors. This is an open-access article distributed under the terms of the Creative Commons Attribution License, which permits unrestricted use, distribution, and reproduction in any medium, provided the original author and source are credited. 